\title{
Hollywood studio filmmaking in the age of Netflix: a tale of two institutional logics
}

\author{
Allègre L. Hadida ${ }^{1} \mathbb{D} \cdot$ Joseph Lampel ${ }^{2} \cdot$ W. David Walls ${ }^{3} \cdot$ Amit Joshi $^{4}$
}

Received: 30 January 2019 / Accepted: 21 January 2020 / Published online: 31 January 2020

(c) The Author(s) 2020

\begin{abstract}
Online streaming services are challenging long-standing decision-making processes in the traditional motion picture industry, thus placing Hollywood major studios at a crossroads. We use the institutional logics perspective to examine how both traditional studios and online streaming services make strategic decisions on which films to produce and how these films are to be distributed. We then apply scenario analysis to explore how their interaction will likely evolve. We argue that the key criteria that studio executives use to make production and distribution decisions are shaped by what we define as a commitment institutional logic: decision-making heuristics that focus their attention on theatrical release and box-office intakes. In contrast, online streaming services follow a convenience institutional logic, the product of advanced data analytics to increase subscriptions. In the convenience institutional logic, the need to drive online traffic by providing users with an extensive catalogue of movies guides film production and distribution decisions. Whereas the commitment logic aims for mass-market hits in cinemas, the convenience logic seeks to reach a wide range of subscribers at home with micro-segmented offerings. We compare the two logics, develop four scenarios of how the interaction between them may shape the film industry, and offer recommendations.
\end{abstract}

Keywords Hollywood studio $\cdot$ Streaming service $\cdot$ Institutional logic $\cdot$ Scenario analysis $\cdot$ Decision-making $\cdot$ Film production and distribution

\section{Introduction}

For almost 100 years, the Hollywood studios ruled the global film industry. They did not always produce the most critically acclaimed films, nor did they dominate in every country. Even so, their market power and box-office returns were unassailable. Lately however, new online content providers have been challenging the continuing

Allègre L. Hadida

a.hadida@jbs.cam.ac.uk

Extended author information available on the last page of the article 
power of the five major Hollywood studios still in operation-that is, Warner Bros. Entertainment, Paramount Pictures, Universal Pictures, Sony Pictures Entertainment, and (after their merger took effect on 20 March 2019) Walt Disney Studios21st Century Fox. Prominent streaming services Netflix and Amazon Studios both engage in multi-billion-dollar investments in content production and appropriate most of the value derived from the shift in global consumer spending from theatrical (from 36.4 billion USD in 2014 to 41.1 billion USD in 2018) to home entertainment (from 15.8 billion USD in 2014 to 42.6 billion USD in 2018: MPAA 2019). Such systemic changes have led to the contention that "Hollywood is in the midst of a full-blown identity crisis". ${ }^{1}$

The identity crisis facing Hollywood is not simply one of an alternative technology eroding its dominance, as was the case in the 1950s when television broadcasting emerged. Rather, a new set of players, online streaming services, are overtly challenging how Hollywood does business. In this article, we contend that to understand this challenge, it is important to contrast the organizing practices (that is, routines and procedures) of the studios with those of the online streaming services. We argue that these organizing practices and the decision-making criteria they give rise to are manifestations of "institutional logics", defined as: "the formal and informal rules of action, interaction, and interpretation that guide and constrain decision makers in accomplishing the organization's tasks" (Thornton and Ocasio 1999: 804). Online streaming services pose a challenge to the institutional logic that governs the studios' decision-making processes. These digital players offer, in contrast to the studios, subscription packages (e.g. Netflix, Amazon Prime, Apple TV+) and single film deals (e.g. Amazon Video, Apple iTunes). ${ }^{2}$ They follow a different institutional logic and consequently use a different set of organizing practices and decision criteria when developing film projects and making distribution decisions. The core question we seek to address is the following: How will the competition between the two institutional logics, one well established and the other new, develop?

The article is structured as follows. The next section introduces the institutional logics theoretical framework. We then proceed to define the two alternative logics that are currently shaping the production and distribution of films. The first, which we label "commitment logic", is the traditional "theatrical release" (that is, the screening of a movie in a cinema) logic of the five Hollywood major studios. The second, which we call "convenience logic", is manifest in the digital libraries and subscription models implemented by newer entrants such as Netflix, Amazon Studios, and Apple TV+. After comparing how the five studios and their digital rivals implement both institutional logics, we turn our attention to the development of alternative scenarios: in particular, scenarios in which the two logics are

\footnotetext{
1 Barnes, B. (2019). A Year after \#MeToo, Hollywood's Got a Malaise Money Can't Cure. The New York Times, 1111 2018: BU1.

2 Other digital platforms, including YouTube, Snapchat and TikTok, also vie for audiences' attention online. Inasmuch as they primarily rely on home-made user-generated content (and in the case of the YouTube TV subscription service, live-streamed television channels), they are not discussed in the present article.
} 
complementary, and others where they compete with, or become substitutes for, one another.

We argue that complementary logics scenarios would reduce the threat to the studios, who would then be able to continue to use digital players as outlets to stream their films after their initial cinema release, and to partner with them to produce and release content both in cinemas and online. Alternatively, competing logics scenarios increase the likelihood of one logic dominating the other. Domination by the commitment logic would result in traditional studios acquiring or developing online streaming services. We already see evidence of such actions, with the launch of Disney+ in November 2019 and of WarnerMedia's and NBCUniversal's bespoke streaming services in 2020. Alternatively, domination by the convenience logic would lead to upstream vertical integration of digital players into traditional studios, as they increasingly seek to expand their portfolios of intellectual property assets and content and to control production facilities. Such integration has also started, with Netflix's October 2018 acquisition of Albuquerque production studio $\mathrm{ABQ}^{3}$ and deal to set up a permanent UK production hub at Shepperton Studios from October 2019. ${ }^{4}$ Last, a scenario of logics substitution could lead to the obsolescence of the two existing logics and the emergence of a new one. We discuss four scenarios articulating these alternatives and offer recommendations to the studios and streaming services. We close the article with our main conclusions and suggestions for further research.

\section{Theoretical overview}

Across the fields of economics and management, extant research has utilized a variety of approaches to explain industry evolution, firm strategy, and managerial decision-making. Notably, scholars have used industrial economics to explain industry dynamics (Porter 1980, 1985), business models to explain firm strategy (Chesbrough 2010), and mental models to make sense of managers' decision-making patterns (Senge 1990; Weick 1995). The institutional logics perspective of strategic decision-making rejects such explanatory segregation. Instead, it proposes a multilevel model that allows for a more comprehensive understanding of observed behaviour by combining industry evolution, internal organizational processes, and managerial cognition.

At the macro-level, institutional logics shape organizing practices that direct and focus the attention of decision-makers (Thornton 2001) on the main production and distribution issues. Institutional logics at firm-level structure practices and routines that studio executives and other organizational actors use to gather information,

\footnotetext{
3 https://edition.cnn.com/2018/10/08/media/netflix-albuquerque-production-studio/index.html. Accessed 10102018.

4 Sweeney, M. (2019). Netflix Strikes Production Deal with Shepperton Studios. The Guardian, 0307 2019, https://www.theguardian.com/media/2019/jul/03/netflix-strikes-production-deal-with-shepperton -studios. Accessed 09112019.
} 
conduct analyses (including market and financial), and map future actions. At the micro-level, institutional logics define cognitive schemata as mental models or heuristics that are the product of interaction between institutional logics and organizing practices at the macro-level (Ocasio 1997; Thornton 2004: 70). These cognitive representations of relationships between actions and consequences guide strategic decision-making and reveal themselves as criteria that studio executives and other organizational actors use to legitimize their decisions to each other and to external stakeholders and audiences.

Once established, the rules and symbols of an institutional logic are internalized, and other logics are perceived as either useless or irrelevant (Haveman and Gualtieri 2017). Schemata usually give rise to "vocabularies of practice"-that is, "systems of labelled categories used by members of a social collective to make sense of and construct organizing practices" (Thornton et al. 2012: 159). These linguistic correlates reinforce the legitimacy and taken-for-granted character of institutional logics, notably by structuring individual cognition and facilitating the social context of the decision-making process. Inasmuch as they serve as "critical linchpins that link symbolic representations with field-level practices" (Thornton et al. 2012: 168), vocabularies of practice bridge the routines and procedures that are institutionalized at the macro- and firm level with individual cognition at the micro-level. They explain how the cognitive diversity of individual decision-makers can produce consistent managerial regularities at the industry and organizational level.

Institutional logics research suggests that decision-makers are slow to abandon organizing practices when performance declines. Such inertia is the result of strong taken-for-granted assumptions governing the relationship between decisions and their consequences. Routinized over time through repeated practice, these assumptions become embedded within institutional logics — ultimately defining what constitutes rational action in a given context. Actors that seek to achieve certain objectives, for instance maximizing returns on investment, are provided with ready-made options from which they select actions that meet desirable performance criteria. This extends not only to criteria used for setting revenue and profit targets, but also to the evaluation of performance relative to preset targets. Thus, institutional logics for a legal firm typically stipulate billable hours as a performance yardstick, and business schools are particularly sensitive to program rankings.

Similarly, if institutional logics shape managerial attention at the individual and organizational levels through mental models, assumptions, and values, then vocabularies of practice provide stability to this attention focus, often to the point of rigidity. They are used both formally and informally, in public deliberations and private discussion. Broadly speaking, they serve two roles. First, they provide individuals with the categories by which they can make sense of the world. In academia, for instance, "tenure", "teaching load", and "research portfolio" function as vocabularies of practice. Second, they serve as tools of justification during decision-making to legitimize preferences and support a proposed course of action (Tilly 2006). In this respect, they are part of the social process that underpins strategic decision-making. The two roles are inseparable, with one inevitably reinforcing the other: The more individuals use vocabularies of practice as tools to communicate and justify their 
views, the more they embed vocabularies of practice as categories that shape individual cognition.

\section{A tale of two institutional logics: commitment versus convenience}

Let us now turn to the "taken-for-granted resilient social prescriptions" (Greenwood et al. 2010: 521) that define the institutional logics of Hollywood studios and online streaming services (respectively). We note that although all studios and streaming services operate under one or the other institutional logic, variations exist in the manifestations of the two logics as practices and decision-making criteria as well as in the schemata and vocabularies of practice across organizations, depending on their culture and history (Haveman and Gualtieri 2017). Table 1 provides a simplified overview of the key attributes of the two institutional logics detailed below. First, we examine the "commitment" institutional logics of the five studios that constitute the core of the Hollywood film industry.

The commitment institutional logic emerged in the early years of the twentieth century, from a close alignment between the feature film-the industry's main product - and the movie theatre as the venue in which the feature film is experienced and consumed (Bowser 1990). Since then, the tight coupling of feature film and movie theatre has framed studio executives' attention and shaped their organizational practices. As organizations, Hollywood studios primarily deal with two key decision areas: what films should be produced, and how these films should be distributed (Gomery 1986 - the Appendix provides a short historical overview of the evolution in time of the commitment institutional logic, starting with the opening of the first nickelodeon theatre in Pittsburgh in 1905).

While the organizing practices and criteria that executives use to decide what films should be produced and how these films should be distributed have evolved over time, the most prevalent among them became internalized in the studios long before they came under the control of larger publicly traded corporations (Simonton 2009). Decisions made during film development and production are explicitly oriented towards theatrical release. Over time, studios developed schemata that regulate the organizational practices underpinning this process: starting with scripts and casting, budgets, the choice of production personnel, and approach to marketing (Ainslie et al. 2005; Basuroy et al. 2006). Nowadays, while the studios finance and release feature films, production relies on mobilizing largely outsourced creative resources (producers, artists, and technicians) on a film-by-film basis (Miller and Shamsie 1996). Mass media promotion designed to attract as much attention from potential audiences as is possible, as soon as possible, accompanies theatrical release. The goal is to create box-office momentum upon release that translates into a profitable theatrical run (Lampel and Shamsie 2000): as a movie delivers high initial (opening weekend) attendance, it should attract media attention and favourable word-of-mouth, which in turn should generate more attendance over the long run, and demand for the film in other distribution channels such as video-on-demandincluding digital streaming. 


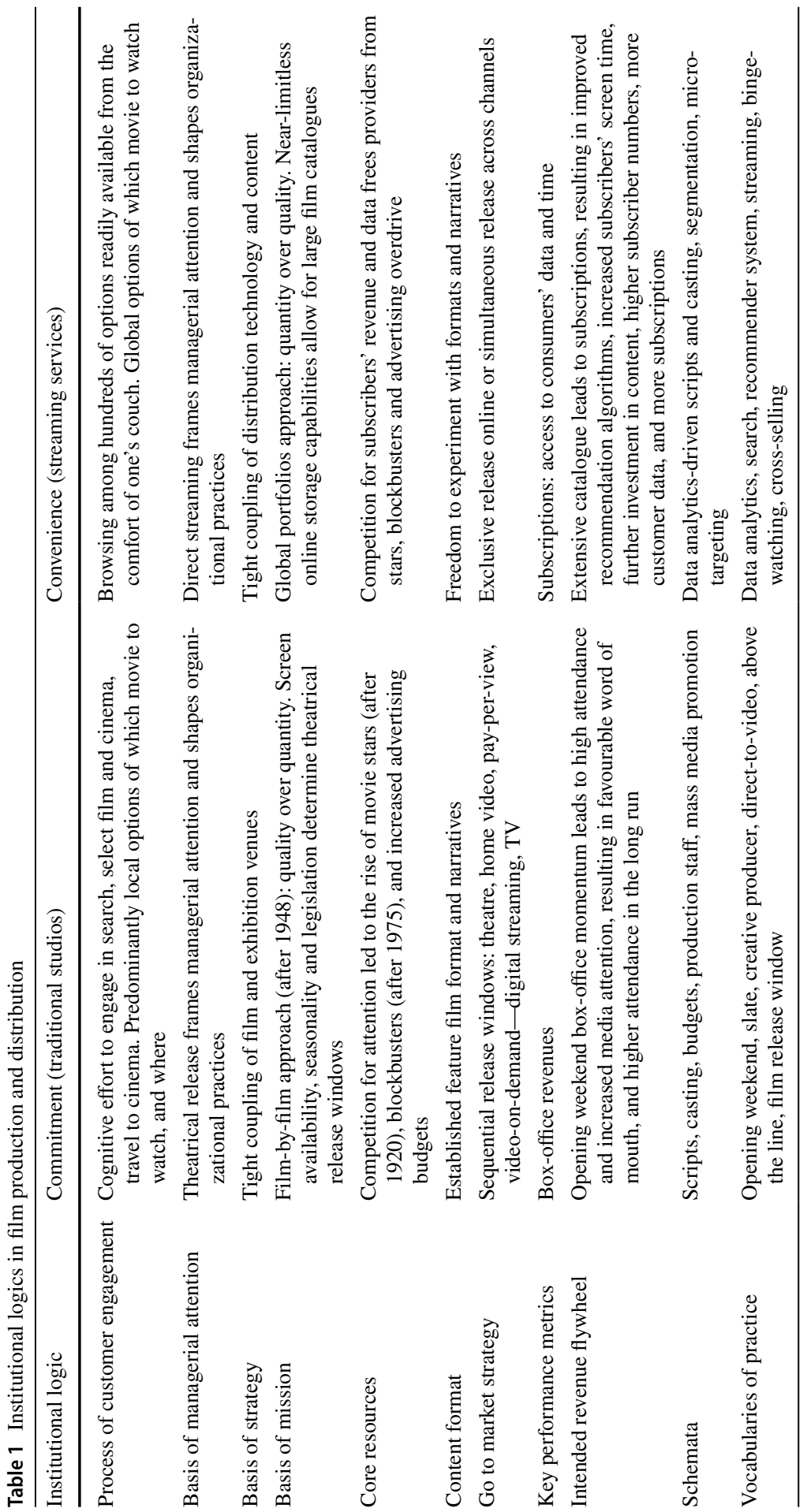


The commitment institutional logic therefore directs a studio's resources to the challenges associated with successful theatrical release, starting with maximizing initial attendance by persuading audiences to commit to spending time and money to what is intrinsically an unpredictable experience. Audiences cannot know in advance how much satisfaction, if any, they will derive from watching a specific movie (Neelamegham and Jain 1999; Walls 2008). Persuading consumers that the experience is worth their effort involves not only motivating them to make the resource commitment needed to go to a cinema instead of taking advantage of the plentiful entertainment alternatives available from the comfort of their home, but also to incur search costs when evaluating alternative film offerings and buy tickets-frequently not just for themselves, but also on behalf of friends, partners, or family.

The commitment institutional logic, with its focus on attracting audiences to cinemas, is ultimately a race to capture consumers' attention before (Jowett 1985) and during a movie's theatrical run (Hennig-Thureau et al. 2006; Sawhney and Eliashberg 1996). The emergence of "movie stars" soon after large studios began to dominate Hollywood was a recognition by studio CEOs of the importance of attracting audience attention to their films (Bass 1994). Studio CEOs initially resisted giving actors special billing. This changed once they realized that movie stars were the surest way of getting audiences to choose which films they wanted to watch (Carrillat et al. 2018; Chang and Ki 2005; Neelamegham and Chintagunta 1999). Alongside the casting of movie stars, studios also invested heavily in sets, special effects, and stories. The resulting increase in budgets reinforced the commitment institutional logic. Getting large audiences into movie theatres fast became essential, and scarce resources were ploughed into movies designed to attract maximum attention from audiences and critics (Ravid 1999).

In the commitment institutional logic, terms such as "opening weekend" (that is, the first weekend box-office revenue of a film), "slate" (the portfolio of films produced or distributed by a studio in a given year), "creative producer" (a producer who actively contributes to creative decisions with the director and screenwriter), "direct-to-video" (a denomination that goes to films that are not deemed good or bankable enough to be released in movie theatres, and are therefore released straight to DVD and Blu-Ray), "above the line" (typically, the producer, screenwriter, director, and lead actors), and "film release window" became the vocabularies of practice that framed attention and shaped organizing practices.

Theatrical release has been central to the commitment institutional logic for over a century, from the first nickelodeon in 1905 to the movie palaces of the 1920s and today's cineplexes. It defines what filmmakers, the film industry, and wider society consider "cinema" to be, prompting director Steven Spielberg to state: "I want to see the survival of movie theaters. I want the theatrical experience to remain relevant in our culture". 5 Other prominent industry players seem to agree on the primacy of theatrical release. According to Cannes Film Festival director Thierry Fremaux, "for a film to become part of history, it must go through theaters, box office, the critics,

\footnotetext{
5 Barnes, B. (2019). Ban Netflix from the Oscars? The New York Times, 2504 2019: B1.
} 
the passion of cinephiles, awards campaigns, books, directories, filmographies. The collective discussion in cafes, in theaters, on the radio. All this is part of a tradition on which the history of film is based [...] the history of cinema and the history of the internet is not the same thing". 6

Exclusivity rules have long defined the relationship between theatrical release and other distribution channels, such as DVD and video-on-demand. Reluctance to compromise on the 90-day exclusivity rule typically in place for blockbuster releases has led leading exhibitors to boycott Netflix movies, including Cary Joji Fukunaga's "Beast of No Nation" (2015), Alfonso Cuaron's Academy Award winner "Roma" (2018), and Martin Scorsese's "The Irishman" (2019). The Hollywood studios feared that agreeing to reduce the 90-day window could set a precedent that would hurt box-office revenues, and compromise the likelihood of other films getting a cinema release. From 2018 onward, movies selected for the Cannes Film Festival also have to commit to being distributed in French cinemas, which under French law, effectively prohibits them from appearing on a streaming platform for 3 years after their theatrical release. ${ }^{7}$ This new rule disqualified de facto "Roma" in 2018 and "The Irishman" in 2019 from being considered for Cannes. ${ }^{8}$

The emergence of Netflix, Amazon Studios, Apple TV+, and other online services that stream content directly to consumers ushered a new institutional logic into film production and distribution, and drove a wedge with traditional industry stakeholders. Near-limitless online storage capabilities allow for large film catalogues that consumers can access at their convenience, in what came to be called "ATAWAD"an acronym that stands for AnyTime, AnyWhere, and on Any Device, including tablets, phones, personal computers, or smart TVs. The reach of online streaming services is global. Netflix, for instance, typically produces content in numerous languages and locations and simultaneously releases it in the 190 countries in which the service operates (Aguiar and Waldfogel 2018). In contrast to the commitment logic, in this alternative "convenience institutional logic", travelling to a bespoke place of consumption becomes unnecessary, and hundreds of options readily available on the streaming services' homepages reduce user search costs to a minimum (Gomez-Uribe and Hunt 2015).

Online streaming services give consumers access to films both produced and commissioned in-house and by traditional studios. They use data analytics to produce and recommend movies, thereby micro-targeting specific groups of consumers upstream and facilitating user search at the point of consumption (Gomez-Uribe and Hunt 2015). Online subscription models, in particular, lower switching costs

\footnotetext{
6 Keslassy, E. (2018). Thierry Fremaux Explains Fest's Thinking on Red Carpet Selfie Ban, Netflix Policy and \#MeToo. Variety, 2303 2018, https://variety.com/2018/film/news/cannes-film-festival-thier ry-fremaux-red-carpet-selfies-1202735264/. Accessed 17012019.

7 Seth, R. (2019). Netflix vs. Hollywood: The Fight to Define the Future of Film. Vogue: Paris Edition, 2503 2019, https://www.vogue.fr/fashion-culture/article/netflix-vs-hollywood-the-fight-to-define-thefuture-of-film. Accessed 05052019.

8 Thaddeus-Jones, J. (2019). Netflix v Cannes: Inside the Battle for the Future of Cinema. Financial Times, 0905 2019, https://www.ft.com/content/494e20b4-70b5-11e9-bf5c-6eeb837566c5. Accessed 10 052019.
} 
by giving consumers the ability to browse through libraries before viewing films in their entirety.

Initially, the film catalogues of online streaming services consisted almost entirely of studio movies. Studios saw online streaming as an additional release window, not fundamentally different from pay-per-view or television, which they could exploit to compensate for the decline in DVD revenue in the early 2000s. They did not realize then that streaming would further reduce DVD sales and rentals. Just as they did in the 1950s when first threatened by television, the studios tried to subordinate streaming to the commitment institutional logic by imposing strict release windows across channels, with theatrical release, which they still regard as crucial for generating the publicity needed to attract consumers, coming first. The studios allow streaming services to keep a relatively small cut of the revenues generated online by their film and television proprietary content, and point to the substantial marketing costs associated with theatrical release to justify this revenue sharing model. Some online film providers, including Netflix and Amazon, have decided to move beyond acting as little more than alternate distribution channel for the studios. They have started producing and commissioning content themselves, in effect taking on the film development role of the studios.

Online streaming services change the relationship between consumers and distributors by replacing commitment with convenience. The convenience logic frees consumers from leaving their home to watch films in movie theatres. It also offers more expansive creative opportunities by liberating filmmakers from the feature film format (that is, the requirement of a running time of about $90 \mathrm{~min}$, long enough for a fully developed cinematic narrative, but short enough for the movie to allow theatres to screen a feature film at least twice during the lucrative evening exhibition schedule), and allowing them to experiment with more varied narrative forms, including shorter films and episodic content. Such flexibility is apparent in the latter, which is no longer constrained to set episode numbers and length, and may vary depending on the nature of the story and viewing experience. For instance, Netflix's December 2018 "Bandersnatch" Black Mirror episode, which offers viewers several alternative narrative options throughout, lasts between 40 and 90 min depending on the different paths the story takes, ${ }^{9}$ and episodes of the 2019 fourth season of Netflix's "Unbreakable Kimmy Schmidt" vary in running time from 22 to $53 \mathrm{~min} .{ }^{10},{ }^{11}$

The convenience institutional logic also frees online film providers from reliance on stars and the constant search for blockbusters. In contrast, the proliferation of ATAWAD content on the 271 streaming services available in the USA alone and the decrease in prices of large flat-screen monitors are forcing studios operating

\footnotetext{
${ }^{9}$ https://www.independent.co.uk/arts-entertainment/tv/news/black-mirror-bandersnatch-endings-how-towatch-all-five-what-happens-netflix-a8703326.html. The Independent, 0201 2019. Accessed 23012019. 10 https://www.imdb.com/title/tt3339966/. Accessed 23012019.

11 As Chavda (2018) points out, this flexibility extends to the commissioning of new shows. Streaming services do not face broadcasting capacity constraints, and the more shows they offer, the more likely they are to attract new subscribers. Most streaming services are also free from the traditional networks' reliance on advertising revenues, and consequently tend to commit to straight-to-series orders rather than experiment with, and overinvest in, the staged development of a handful of pilots only into full series.
} 
under the commitment logic to sustain theatrical attendance by focusing even more resources on developing tentpole movies. Cinema ticket prices have increased since 2010, so nowadays, "A movie has to feel like an event. Otherwise, people say, 'Ehh, let's just watch Netflix",. 12

The risks that attend the commitment logic_-spending on blockbusters, and movies featuring stars that attract audiences into cinemas but appropriate substantial portion of box-office revenues (De Vany and Walls 1999; Faulkner and Anderson 1987; Ravid 1999) — are largely eliminated in the convenience logic under which streaming services operate. When betting on box-office hits ceases to be the driving force, the emphasis on casting stars and ensuring production quality diminishes. Production volumes take precedence, production budgets get smaller, and distribution costs become almost negligible.

Online film providers use their consumer base, market power, and substantial cashflow to produce their own content. For instance, Amazon plans to roll out 30 original movies a year with budgets of up to 50 million USD and to release most of them, including "date-night" and specialist horror films, directly on Prime Video. ${ }^{13}$ Similarly, of Netflix's intended yearly output of 55 movies per year, 35 have budgets of up to 20 million USD, with a majority (75\%) consisting in genre movies designed to appeal to hyper-segmented target consumers ${ }^{14}$ whose profiles are primarily determined using advanced data analytics. ${ }^{15}$ Online streaming services occasionally cast movie stars in their higher budget films or shows-essentially to increase visibility and attract more subscribers.

Online film providers also transact business with studios on their own terms. Apple and "Moonlight" (2016) and "Ladybird" (2017) producer A24, ${ }^{16}$ Amazon and "The Purge" (2013) producer Blumhouse, ${ }^{17}$ and Netflix and Paramount Pictures ${ }^{18}$ recently struck production deals. In a twist on the studios' commitment logic, Amazon and Netflix intend to offer limited theatrical release to those films most likely to get high-profile nominations and awards, which in turn serve to incentivize prominent filmmakers to work with them and bestow prestige on the service, thus increasing its awareness among potential new subscribers and, therefore, generating more

\footnotetext{
12 Barnes, B. (2019). In the Shadow of Blockbusters, Smaller Films Wilt. The New York Times, 2411 2019: BU1.

13 Barnes, B. (2019). Amazon Resets Its Film Operation After Rough Year at Box Office. The New York Times, 1902 2019: B1.

14 Barnes, B. (2018). Netflix's Movie Blitz Takes Aim at Hollywood's Heart. The New York Times, 17 12 2018: A1.

15 Adalian, J. (2018). Inside the Binge Factory. The New York Magazine, 11062018.

16 Bradshaw, T. (2018). Apple strikes movie deal with Moonlight producer A24. Financial Times, 1511 2018, https://www.ft.com/content/c295acb8-e91e-11e8-885c-e64da4c0f981. Accessed 15112018.

17 Barnes, B. (2019). Amazon Resets Its Film Operation After Rough Year at Box Office. The New York Times, 1902 2019: B1.

18 Paramount Chief Executive Jim Gianopoulos's description of the deal as a "new, incremental revenue stream" demonstrates the enduring prevalence of the commitment logic at the studio (in Nicolaou, A. (2018). Paramount Agrees Deal to Make Films for Netflix. Financial Times, 1611 2018: https://www. ft.com/content/ac466e72-e999-11e8-885c-e64da4c0f981. Accessed 16112018.
} 
subscription revenue. ${ }^{19}$ Even so, as Sperling (2019) notes, "Netflix has little time for the old theatrical business model. It is devoted to keeping its subscribers happy, meaning that most of its movies make their debuts on the streaming service itself". ${ }^{20}$

Although both Netflix and Amazon adhere to the convenience logic, their approaches differ. Whereas Netflix uses premium content to generate more subscriptions to its streaming service and fend off competitors, Amazon uses every element of the Amazon Prime service, including award-winning content, to generate crossselling. The intention is to use Prime customers' annual membership fee to encourage more browsing and purchases: as CEO Jeff Bezos explains, "when we win a Golden Globe, it helps us sell more shoes". ${ }^{21}$

In the convenience logic, performance is assessed as the total number of subscribers on a global portfolio rather than a film-per-film basis, and data analytics efforts are directed towards compelling subscribers to stay on the service longer. As Gomez-Uribe and Hunt (2015: 13:2) note: “... a typical Netflix member loses interest after perhaps 60 to $90 \mathrm{~s}$ of choosing, having reviewed 10 to 20 titles (perhaps three in detail) on one or two screens. The user either finds something of interest or the risk of the user abandoning our service increases substantially. The recommender problem is to make sure that on those two screens each member in our diverse pool will find something compelling to view, and will understand why it might be of interest". ${ }^{22}$ Theatrical release is no longer a priority and is often forfeited altogether by streaming services, unless, as previously mentioned, a limited scale release is deemed necessary to secure participation from highflying talent and gain Oscar nominations for specific movies, which in turn helps to increase the visibility of the service and the number of its subscribers.

Online content providers are mostly free from the geographic distribution constraints of the Hollywood studios. Thus, they can grow their business "on an enormous scale...becoming a producer and distributor of shows and movies with a fully global reach" (Gomez-Uribe and Hunt 2015: 13:6). As of October 2019, Netflix had over 158 million subscribers worldwide, including 62 million in the USA, ${ }^{23}$ and in June 2019, Amazon Prime boasted 105 million paying members in the USA alone,

\footnotetext{
${ }^{19}$ Kenigsberg, B. (2018). Netflix Put a Movie in Theatres. Good Luck Finding It. The New York Times, 1411 2018: B1.

${ }^{20}$ Sperling, N. (2019). Netflix and Theatre Chains Feud Over 'Irishman'. The New York Times, 0311 2019: BU, 1.

${ }^{21}$ Mossberg, W. (2016). Five Things I learned from Jeff Bezos at Code. The Verge, 0806 2016, https:// www.theverge.com/2016/6/8/11879684/walt-mossberg-jeff-bezos-amazon-blue-origin-code-conference -2016. Accessed 02052019.

${ }^{22}$ Netflix is consequently seeking to limit password sharing, which by compromising the accuracy of its recommender algorithms and circumventing its business model, adds up to millions of dollars of unachieved income. The Independent, 1810 2019, https://www.independent.co.uk/arts-entertainment/ tv/news/netflix-password-sharing-account-details-friends-family-stream-a9162186.html. Accessed 1910 2019.

${ }^{23}$ https://www.statista.com/statistics/250934/quarterly-number-of-netflix-streaming-subscribers-world wide/. Accessed 08112019.
} 
although not all of them used Prime to stream audio-visual content. ${ }^{24}$ These numbers are dwarfed, however, by Apple's 1.4 billion devices in use around the world as of February 2019, including over 900 million iPhones, which screens Apple TV+ is intent to fill with its own content and programming from partner companies. On 1 November 2019, Apple TV+ joined a fierce battle for subscribers, or more precisely, for "credit card numbers, email addresses and direct access to consumers". 25 Apple profits from its reputation for quality and security to offer subscription packages at 4.99 USD a month — that is, 4 USD cheaper than Netflix's basic subscription and 11 USD cheaper than its premium membership. Students who subscribe to Apple Music for 4.99 USD per month get Apple TV+ on top, and buyers of a new Apple device access the new service free of charge for 1 year. ${ }^{26}$

Although the convenience institutional logic is younger than the commitment institutional logic, it has also already spawned its own vocabularies of practice, such as "data analytics", "search", "recommender system" (that is, a collection of algorithms that come together to offer bespoke viewer recommendations), "streaming", "binge-watching" (a tailored viewing experience normalized by Netflix that structures its publishing and business model: Jenner 2018), and "cross-selling" (selling an additional product or service to an existing customer).

\section{Competition, cooperation, and substitution between institutional logics}

Institutional logics exercise considerable influence on decision-making within firms and across industries. However, early studies argued that when changes take place in the business environment, this influence may decline, with institutional logics that are unable to adapt to the new conditions often replaced by new ones (Thornton and Ocasio 1999). More recent work contends that institutional logics that run into difficulties can also evolve by assimilating new practices, by expanding or contracting their scope, by blending (that is, hybridizing) with other institutional logics, or by splitting into multiple institutional logics (Thornton et al. 2012: 164). Organizations may also use institutional logics as resources which they strategically incorporate or discard to improve their competitive position and performance within an industry. Thus, when a new logic emerges, and depending on their competence base, scope of operations, and status position, organizations can opt to persist with their original logic, or to embrace the new logic so as to overhaul established competitive positions by either adding or substituting it for the existing logic (Durand et al. 2013).

The institutional logics perspective presents a range of alternatives that are useful to analyse how the interaction between commitment and convenience may play out. The options discussed below do not offer a forecast. Rather, they accommodate the

\footnotetext{
24 https://www.statista.com/statistics/546894/number-of-amazon-prime-paying-members/. Accessed 08 112019.

25 Lee, E. (2019). Netflix Out as Apple Ramps Up Programs. The New York Times, 2503 2019: B1.

26 https://www.digitaltrends.com/apple/what-is-apple-tv-plus/, 0111 2019. Accessed 08112019.
} 


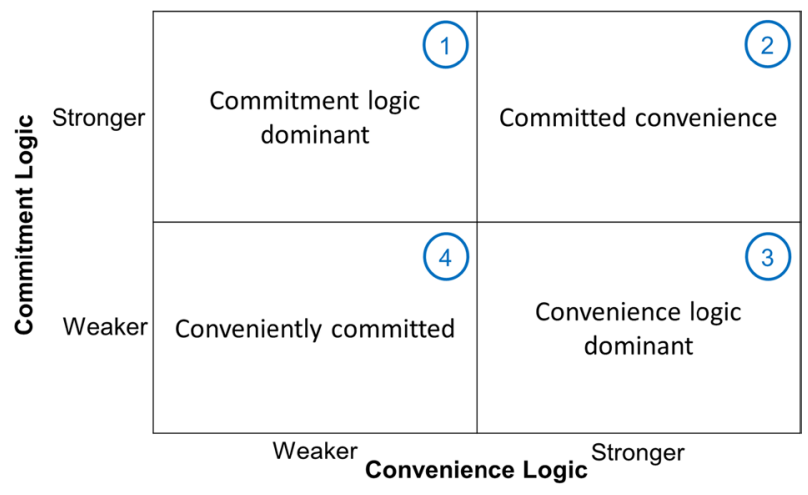

Fig. 1 Institutional logics scenario matrix

uncertainty of the decisions and actions of the studios, online streaming services, and other key stakeholders in the face of a rapidly changing environment. Such uncertainty makes knowing for sure what will happen impossible. Even so, we can flesh out possible scenarios by constructing alternative combinations between the two logics, and the strategic moves that they entail for the Hollywood studios and online streaming services. Figure 1 presents a matrix of four such scenarios.

\subsection{Commitment logic dominant}

In this first scenario, the commitment and convenience logics still coexist; however, the former dominates the latter (Nigam and Ocasio 2010). The extreme risk associated with wide theatrical release is perceived as an asset rather than a liability, and unbounded risk (infinite variance) arises from the upside potential of a motion picture's revenues (De Vany and Walls 2004). Traditional studios and exhibitors strive to improve the experience of going out to watch a movie in a cinema: the first by increasing the level of excitement associated with blockbuster movies combining marquee talent, heavy marketing, and a wide opening (Elberse 2013), and the second, by enhancing the comfort of the seats and the quality of the sound, image, and food and drinks available in cinemas. In many ways, scenario 1 is the alternative with the highest uncertainty associated with success, as it perpetuates the high cost strategy of releasing films in cinemas by still aiming for high returns in a marketplace exceedingly skewed towards a very small number of blockbusters (De Vany and Walls 2004; Walls 2013) hailing from increasingly consolidated studios.

In scenario 1, the online streaming services continue to use data-driven analytics to micro-segment their offerings and produce and broadcast niche content that is narrowly marketed to specific audiences. Just like independent film third-party 
finance changes the entire distribution of film earnings by reducing both the probability of losses and of high returns (Rusco and Walls 2004), and the online streaming services focus primarily on episodic content that provides a low-variance flow of revenues, thereby reducing the risk of losses along with the prospect of extremely large profits. They consequently end up competing for content and viewers with digital television channels, rather than with Hollywood studios.

In contrast, the traditional studios increasingly focus on the production and distribution of a few tentpole blockbusters a year, and enjoy robust earnings through a combination of technological evolution (for instance, virtual or augmented reality), marketing savvy, and institutional knowledge. Occasional large successes and studio mergers provide the critical mass and resources needed to pursue this logic. In scenario 1 , Hollywood studios continue to use streaming services, including their own, as one of many channels for their films, with a significant delay between theatrical release and online streaming. Studios may also renew or develop partnerships with start-ups that operate under the commitment logic, for instance Red Carpet Home Cinema, which allows 36-h movie rentals upon release for 1500-3000 USD per film. ${ }^{27}$

Scenario 1 prolongs the commitment logic that currently prevails within the traditional Hollywood studios by expanding its scope at the expense of the convenience logic. It is manifest, for instance, in the closing down or streamlining of many major studio specialist divisions and in the steady decrease in original and art house productions to focus on blockbuster franchises, sequels, and adaptations.

\subsection{Committed convenience logic}

When two institutional logics interact, one can absorb the key elements of the other, leading to a "blending" of the two (Glynn and Lounsbury 2005). In our second scenario of "committed convenience", the studios fully embrace data analytics to produce a varied portfolio of audio-visual content which they either still traditionally distribute using a blockbuster strategy or digitally stream without a theatrical release. Meanwhile, online streaming services multiply their forays into cinemas, and end up also adopting a blended approach of production and theatrical distribution of tentpole blockbusters and of production and online streaming of episodic content and small and mid-budget movies.

Traditional studios dominate in the committed convenience logic, primarily because they can integrate into streaming more easily than online firms can diversify into blockbuster production. They do so either by developing a streaming platform organically and relying on the appeal of their existing film catalogue to build critical mass, or by acquiring the catalogue and technology of an existing streaming service. Scenario 2 allows traditional studios to leverage their legacy deals and relationships to talent, technical services, and exhibitors to continue to pursue a traditional blockbuster strategy in movie theatres, while simultaneously adopting the uncertainty

${ }^{27}$ Barnes, B. (2019). $\$ 3,000$ to Rent a Movie? Bringing the Theater Home for the $1 \%$. The New York Times, 0804 2019: B1. 
reduction techniques of data analytics and boutique offerings which online providers favour. To stay relevant and embrace the disruption caused by online streaming, some studios may therefore become "reinvented incumbents" that use "many of their established advantages of scale and access to capital to achieve greater economic returns compared with their traditional counterparts". ${ }^{28}$

We see elements of this scenario in progress, for instance, within Walt Disney Studios-21st Century Fox, which are simultaneously heavily investing in traditional tentpole blockbusters such as Anthony and Joe Russo's 2019 “Avengers: Endgame" and operating the new "Disney+" online streaming platform. The latter was launched with considerable cross-promotional clout ${ }^{29}$ on 12 November 2019 for 6.99 USD per month (it is free for 1 year to Verizon unlimited phone plan subscribers) to complement Disney-owned Hulu, ${ }^{30}$ which may also pivot to more mature content moving forward. ${ }^{31}$ Disney+ signed in 10 million subscribers in its launch week. ${ }^{32}$ WarnerMedia and NBCUniversal are also developing proprietary streaming services, which they intend to launch in $2020 .{ }^{33}$ All are actively reclaiming their copyrighted content from existing online services to offer it exclusively on their upand-coming platforms. ${ }^{34}$

\subsection{Convenience logic dominant}

Scenario 3 offers a reversal of scenario 1, with a similar process leading one institutional logic to expand at the expense of the other. Here, however, the convenience logic comes to dominate the commitment logic. As the prominence of traditional studios wanes and the requirement of theatrical distribution disappears, convenience becomes the dominant logic. Online streaming services are able to provide sustainable low-variance returns on boutique content through the use of data analytics and recommender systems (Gomez-Uribe and Hunt 2015). Already lower uncertainty for online providers is further decreased as they collect more data and improve their artificial intelligence algorithms and as more people migrate online, leading

\footnotetext{
28 Pacthod, D., Sneader, K. \& Swaminathan, A. (2018). Why Legacy Companies Must Reinvent-or Die. Fortune, 2409 2018, http://fortune.com/2018/09/24/business-strategy-technology-mckinsey/. Accessed 05052019.

29 Barnes, B. (2019). Disney is New to Streaming, but its Marketing is Unmatched. The New York Times, 2710 2019, https://www.nytimes.com/2019/10/27/business/media/disney-plus-marketing.html. Accessed 09112019.

30 Disis, J. (2019). Disney is Taking Full Control of Hulu. CNN Business, 1405 2019, https://editi on.cnn.com/2019/05/14/media/disney-buys-comcast-hulu-ownership/index.html. Accessed 18052019.

31 Gartenberg, C. (2019). AT\&T May Have Just Signaled the End of Hulu as You Know It Today. The Verge, 1504 2019, https://www.theverge.com/2019/4/15/18312068/disney-hulu-att-sells-stake-comcastcontrol-streaming. Accessed 02052019.

32 Swisher, K. (2019). Disney Channels the Force. New York Times, 1511 2019, https://www.nytim es.com/2019/11/15/opinion/disney-plus-streaming-netflix.html. Accessed 28112019.

33 Nicolaou, A. \& Fei, F. (2019). Netflix: How Will the Story End? Financial Times, 1809 2019, https:// ig.ft.com/netflix-future/. Accessed 08112019.

34 Bode, K. (2019). The Worst May Be Yet to Come for Netflix. OneZero Medium, 2607 2019, https ://onezero.medium.com/the-worst-may-be-yet-to-come-for-netflix-2a429ed9c4f6. Accessed 30072019.
} 
to the positive feedback loops generally referred to as data network effects or "data flywheel". 35

An extreme version of scenario 3 may see the disappearance of movie theatres, and the replacement of what would become outdated film festivals and film awards with new status markers and more encompassing selection systems incorporating feature films and episodic shows. In a more conservative convenience logic dominant scenario, online streaming services would still engage in a few theatrical releases, perceived as prerequisites to creating or signalling status markers and to gaining industry prestige (Durand and Hadida 2016; Webster and Hysom 1998). Both Amazon Studios and Netflix have experimented with theatrical release, and both have mostly done so to create awareness for their movies, to qualify for awards, and to court filmmakers whose preferred release channel remains the big screen. ${ }^{36}$ Moving forward, they may use their capabilities and competitive advantage in data analytics to harness the knowledge from these initial experiments and make theatrical release a more standard part of their go-to-market strategy.

A plausible development under the convenience logic dominant scenario would therefore see online streaming services integrate downstream into cinemas to decrease the cost of theatrical distribution. Accordingly, Amazon and Netflix were both in the running in 2018 to acquire Landmark, an independent and foreign film focused movie chain operating over 50 cinemas in the USA. ${ }^{37}$ Netflix also took over the lease of historic "Paris" movie theatre in New York City in November 2019 and will use it to showcase some of its most prestigious films, starting with Noah Baumbach's 2019 "Marriage Story". 38

In scenario 3, a consolidation of digital streaming services is also possible. For instance, Apple may purchase Netflix, which had amassed by the end of 2018 over 29 billion USD in debt and obligations to finance its growth and committed additional spending of $2-5$ billion USD over the next 5 years, ${ }^{39}$ to accelerate its plan to create original content and to get access to Netflix's growing international catalogue of bespoke audio-visual properties. ${ }^{40}$ Similarly, Apple or Amazon may also use their cash reserves to purchase one Hollywood studio, for instance Paramount Pictures,

\footnotetext{
35 https://www.cbinsights.com/research/team-blog/data-network-effects/. Accessed 23012019.

${ }^{36}$ Fithian, J. (2019). A Way for Netflix to Add to its Bottom Line: Include Theatres in the Mix. Variety, 1101 2019, https://variety.com/2019/film/news/netflix-add-theaters-john-fithian-nato-1203106077/. Accessed 02052019.

${ }^{37}$ Musil, S. (2018). Netflix Has Reportedly Considered Buying Movie Theaters. CNet, 1904 2018, https ://www.cnet.com/news/netflix-has-reportedly-considered-buying-movie-theaters/. Accessed 1911 2018; Sakoui, A., Ahmed, N. \& Soper, S. (2018). Amazon in Running to Acquire Landmark Movie Chain. Bloomberg, 1608 2018, https://www.bloomberg.com/news/articles/2018-08-16/amazon-is-said-to-be-inrunning-to-acquire-landmark-movie-chain. Accessed 19112018.

38 https://www.cnbc.com/2019/11/26/netflix-takes-over-new-yorks-paris-theater-for-movie-screenings .html. Accessed 20122019.

39 Nicolaou, A. \& Fei, F. (2019). Netflix: How Will the Story End? Financial Times, 1809 2019, https:// ig.ft.com/netflix-future/. Accessed 08112019.

${ }^{40}$ Rocco, M. (2019). Apple Should Buy Netflix, Sonos or Activision Blizzard, JPMorgan Says. Financial Times, 0402 2019, https://www.ft.com/content/93dc4694-2892-11e9-a5ab-ff8ef2b976c7. Accessed 01052019.
} 
then liquidate or integrate most of its production facilities to focus on exploiting its film catalogue.

\subsection{Conveniently committed logic}

The fourth and last scenario, "conveniently committed", is one in which both the commitment and the convenience institutional logics are challenged. Scenario 4 is based on considering the possibility of a transformation in the industry that leads to the emergence of a novel institutional logic that ultimately replaces existing ones (Rao, Monin, and Durand 2005).

Traditional studios did not anticipate the advent of the convenience logic. Paramount Pictures was reported as "[missing] internet opportunities at nearly every turn" in the 25 years since Viacom acquired the studio in $1994 .{ }^{41}$ In 2010, the then Time Warner Chief Executive Jeffrey L. Bewkes famously underestimated the threat posed by Netflix, which he described in the following terms: "It's a little bit like, is the Albanian army going to take over the world? I don't think so". ${ }^{42}$ Arguably, Time Warner was also reluctant to jeopardize the lucrative multi-billion-dollar relationship with cable networks by "charging into the streaming fray" ${ }^{43}$ By early 2020 though, 46 million consumers, or one in five adults in the USA, have cancelled their pay-tv subscription. ${ }^{44}$ Just as the traditional studios did not foresee the challenge from streaming services, the emergence of a new, yet to appear logic may similarly blindside both extant traditional studios and online streaming services.

In scenario 4, online streaming services may find that intermittent binge consumption and low switching costs between online streaming services prevent them from retaining subscribers for substantial periods of time. Digital television channels and other forms of online entertainment may exacerbate the instability of their subscriber base. At the same time, the studios may continue to struggle with an increased prevalence of film viewing ATAWAD by consumers on their own or in small groups. This may lead traditional studios to conclude that continuing to pursue blockbuster strategies driven by theatrical exhibition has become unsustainable.

A new institutional logic radically different from both commitment and convenience may therefore emerge. Part of the challenge both institutional logics face comes from the changing nature of content consumption. The shared, communal experience of watching a film in the darkness of a movie theatre surrounded by strangers has long defined cinema and has long been a unique value proposition of the commitment logic. Enjoying filmed entertainment in the privacy of one's home removes an important part of this experience. The consequences can be significant.

\footnotetext{
41 Chozick, A. \& Barnes, B. (2019). Hollywood's Mountain, Now a Molehill. The New York Times, 20 01 2019: BU1.

42 Arango, T. (2010). Time Warner Views Netflix as a Fading Star. The New York Times, 13122010 : B1.

43 Barnes, B. (2019). The Streaming Era Has Finally Arrived. Everything Is About to Change. The New York Times, 0112 2019: F3.

44 Barnes, B. (2019). Disney Debut Shows Streaming's Force. The New York Times, 1111 2019: B1.
} 
The emergence of television broadcasting in the 1950s resulted in a shift in audience demographics and a sharp decline in the average age of regular moviegoers (Gil and Spiller 2007; Segrave 1999). The cohort of young people that drove cinema attendance prior to online streaming is now coming of age in an environment where consuming recorded entertainment whenever, wherever, and on any device has become the norm.

The emergence of contemporaneous mass viewing without physical co-presence is particularly significant in scenario 4. Large numbers of individuals can now view the same program on hand-held devices simultaneously in different locations, and submit themselves to a shared experience that previously could only be provided in cinemas or by inviting friends to watch content together at home. By engaging with social media and online forums, viewers can now watch content and share comments online in real time with friends, acquaintances, and complete strangers. Technological developments such as augmented reality may hasten and enhance such occurrences.

We therefore foresee an evolution of viewer preferences for streamed content on hand-held screens as a plausible and acceptable substitute for theatrical viewing. In scenario 4, new online business models as well as platforms providing the functionalities and experiences of existing services as part of their own expanded offerings (Eisenmann et al. 2011) may emerge and supplant both traditional studios and online streaming services. More revolutionary developments under scenario 4 could also make film production and consumption obsolete. Contemplating one such radical scenario, Netflix's co-founder and CEO Reed Hastings goes as far as to say: "I worry about a pharmaceutical company inventing a pill providing better entertainment than our movies. Substitutions like this or the misuse of AI could change our markets and behaviour-for the worse". 45

\section{Discussion and conclusion}

In this article, we identified two institutional logics at play in the current filmmaking ecosystem: the traditional logic of commitment developed and implemented by the five major Hollywood studios, and a new, emergent logic of convenience spearheaded by Netflix, Amazon Studios, and other online streaming services. We set out to review these two logics and define their key features, before exploring four alternative scenarios aimed at illustrating how competition, cooperation, or co-opetition (Brandenburger and Nalebuff 1996) between the two institutional logics, one established and the other new, may develop in the near future.

The institutional logics approach, which serves as the theoretical underpinnings of our research, is strongly socio-cognitive in nature. As previously stated, it argues that the attention and the decision-making criteria and actions of managers and organizations are partly determined by the institutional logic under which

45 https://www.hec.edu/en/news-room/hastings-shares-rare-insight-netflix-blast. 2509 2019. Accessed 09112019. 
they operate. The traditional studios' institutional logic of commitment rests on a dynamic interaction between executives who are primarily focused on production and executives strongly oriented towards distribution. Such interaction provides both the cognitive framing and the legitimation of the arguments put forward in our discussion.

Our research brings a clear institutional logics focus to the drive to identify the rationales underlying strategic processes and decisions and eliciting the development of competitive advantage (Regnér 2005). We also offer the first institutional logics framing of the rivalry between traditional studios and online streaming services. Applied to the film industry, the institutional logics perspective differs markedly from prior approaches taken in the economics (Moul 2005; Vogel 2014), finance (Rusco and Walls 2004), and marketing (Elberse and Eliashberg 2003) literature. Just like most quantitative studies of other cultural products including books, music, and games (see, for instance, the numerous studies cited and discussed in HennigThureau and Houston 2019), nearly all quantitative research on the movie business so far has focused on project-level analyses of the correlates of film profitability. It has consequently derived managerial implications specific to the production and distribution of individual films, such as the use of marquee talent or promotional activity. While this line of research provides useful normative guidance for the production and distribution of individual titles, it may not be particularly helpful in guiding the stream of decisions that studios have to make in their role as major hubs of financing, production, and distribution of feature films. Our approach provides an overview that is consistent with this strategic task.

This article is also the first, to the best of our knowledge, to combine institutional logics with scenario analysis. At this stage however, our effort very much focuses on analysing existing industry conditions. A deeper analysis could involve, for instance, identifying and expanding on some of the factors that could push specific organizations or the overall industry towards each of the scenarios. While a thorough analysis of these factors and of the likely results of their combination is beyond the scope of the current article, three of them deserve particular attention.

First, as streaming services keep growing and consolidating, anti-trust regulations may lead governments in certain jurisdictions to argue that they represent a monopsony power that needs to be curtailed, for the benefit of consumers and of their own domestic film industries. Such a development would favour scenario 2. Second, digital privacy concerns may lead legislators to place limits on the right of streaming services to use recommender systems that rely on user generated data. Regulations that require streaming services to obtain consent from consumers for the use of viewing data will reduce the predictive power of recommender systems that is currently central to the streaming services' convenience logic. Such conditions would favour scenario 1 . Third, changing consumer habits may lead to a radical redefinition of the current movie theatre landscape. Cinema attendance has been decreasing steadily and is now at an all-time low (MPAA 2019). Outside emerging markets such as China and India, exhibition revenues have been strong primarily because ticket prices have risen sharply. Should the decline in attendance continue, moviegoing may entail discretionary spending comparable to that of live theatre attendance. Film exhibition may become at best a niche business (Baumol and Bowen 1966), 
as the current multiplex exhibition system loses economic viability, leading many exhibitors to exit the industry. In such conditions, the standard studio distribution model that relies on theatrical release would become unsustainable. Scenario 3 or scenario 4 would then be favoured.

Additional considerations and modelling of the risks and rewards involved with each of the four scenarios and an empirical assessment of the cost-to-benefit ratio associated with them could also expand the current research. Another follow-up study could consist of a more detailed analysis of the decisions taken by specific studios and streaming services in the light of the four proposed scenarios, and of the impact of their actions on performance and competitiveness. A study of how people and organizations deal with the institutional changes implied by the four scenarios, focusing in particular on resistance to change and lock-in, would also provide interesting material for a qualitative case study.

Focusing on Hollywood inevitably means that we have essentially adopted a US-centric approach. It is important to note that institutional logics are historically contingent and vary over time and across geographies (Friedland and Alford 1991; Haveman and Gualtieri 2017). It would therefore be interesting to test whether the same approach can be used to analyse other national film industries with different distributions of power among social actors, technologies in use, and performance metrics. For instance, further research could examine whether the approach outlined in this article applies to China or the European Union, which confront the challenge of online streaming without a powerful integrated studio system in place.

Management research tends to use historical data to explain the contours of today's business. Our article does not have this luxury: the motion picture industry is in flux. Reports of strategic moves from either side of the institutional logics spectrum hit the news almost daily, and Hollywood studios' revenues are affected by two loop effects: they simultaneously compete with the disruptive business models of the streaming services and create more intense competition with each other (Bughin and van Zeebroeck 2017). Our article therefore explores potential trajectories, without concluding which of them will be realized.

Even so, our analysis does lead to the following recommendations. The main normative implication for managers is to view the industry through the lens of institutional logics. Decision-makers within studios and streaming services need to be cognizant of changes in institutional logics and organizing practices. The move from individual product pricing to subscription has also affected exhibitors, with apps such as MoviePass challenging existing models. Over time, we can expect more such innovative challengers attempting to disrupt the existing order.

Second, irrespective of the dominant institutional logic, data analytics are likely to be key drivers in the evolution of the film industry. Online streaming services are fairly advanced in their use of analytics, while traditional studios seem to be playing catch up. The institutional logics perspective points to organizations potentially becoming more similar in time, for instance through the mobility of human capital among them. Online streaming services regularly hire traditional media executives. Among them, former president of entertainment at NBCUniversal Jennifer Salke joined Amazon in February 2018 to oversee its studio business, and former chief creative officer of UK's Channel 4 Jay Hunt joined Apple in October 2017 to head 
the firm's worldwide video operations. Likewise, expanding their recruitment and promotion policies to a new class of managers who understand and relate to the convenience institutional logic and empowering them to make decisions may help traditional studios advance their understanding and perception of this latter logic. It may also help them make pertinent decisions relative to what data analytics capabilities they need to develop, and what resources they need to invest to do so.

Third, all players, but especially streaming services, should closely monitor new technological developments. Since the success of the latter is largely based on changing consumer habits due to technology (for instance, ubiquity of broadband access, rapid growth in hand-held devices, and the social connectivity from Internet 2.0), it makes them more vulnerable to newer technologies, and therefore potential competitors or substitutes, than traditional studios. Augmented reality may soon provide theatre-level visual experiences from the comfort of one's home, while also allowing simultaneous social connectivity across multiple physical locations.

The four scenarios developed in this article are intended to help all players delineate and inform their next strategic moves. Our hope is that industry experts find them useful standpoints for their analyses, at a time when the perception that "nobody knows anything" in the film business (Goldman 1983) may be stronger than ever.

Acknowledgements The authors are grateful to the Special Issue Guest Editors and three anonymous reviewers for their helpful and constructive comments. We also thank Guilhem Bascle, Pierre-Jean Benghozi, Richard Campbell, Xavier Martin, Ashley Metz, Marius T. H. Meus, Leon Oerlemans, Nuno Oliveira, Hans Van Dijk, Hugh Wood, and participants at the 2019 Mallen Motion Picture Economics Conference and the 2019 AIMAC Conference and at research seminars hosted by University of Tilburg and Louvain-la-Neuve Université for feedback and suggestions. Finally, we wish to thank Charles Dickens and Walter Benjamin for inspiring our title, and all the filmmakers, producers, distributors, and content providers named in the article for wonderful hours of procrastination (and by hours, we mean weeks).

Open Access This article is licensed under a Creative Commons Attribution 4.0 International License, which permits use, sharing, adaptation, distribution and reproduction in any medium or format, as long as you give appropriate credit to the original author(s) and the source, provide a link to the Creative Commons licence, and indicate if changes were made. The images or other third party material in this article are included in the article's Creative Commons licence, unless indicated otherwise in a credit line to the material. If material is not included in the article's Creative Commons licence and your intended use is not permitted by statutory regulation or exceeds the permitted use, you will need to obtain permission directly from the copyright holder. To view a copy of this licence, visit http://creativecommons.org/licen ses/by/4.0/.

\section{Appendix: A brief historical overview of the commitment institutional logic}

The expansion of fixed "nickelodeon" movie theatres between 1905 and 1907 led to the take-off of cinema as a legitimate industry (Musser 1990) and to the emergence of the commitment institutional logic. It coincided with a significant increase in film production and the development of distribution as a special activity often managed by large film production companies (Bakker 2007).

By the end of the 1920s, longer feature films were shown in comfortable "movie palaces", with talking movies becoming mainstream after the release of Alan 
Crosland's “The Jazz Singer" in 1927. Up until the early 1950s, studios made as many as fifty movies a year each, with audiences to match. Two major external shocks caused the end of this "golden age" (Gomery 1986), and the ensuing strengthening of the commitment logic. First, the 1948 anti-trust Paramount Decrees led to a separation of exhibition from production and distribution and to the prohibition of many of the standard trade practices of the day, including block booking, blind bidding, and master licence agreements, that contractually guaranteed theatre screens for a studio's entire annual slate. ${ }^{46}$ Signatories to the Decrees-Paramount, Loew's (MGM), Warner Bros., 20th Century Fox, RKO Pictures, Universal Studios, and United Artists - divested from their theatrical assets and abandoned a portfolio approach to development and sales, opting instead for a film-by-film approach. Second, the surge of television-from 14,000 sets in 1947 to covering almost $90 \%$ of US households by the end of the 1950s-led to an increase in demand for quality content.

By the 1960s, studios had embraced television as a viable outlet for their movies. By shifting their mass production efforts into episodic television and lower-quality "made-for-television" movies, they were also able to reorganize their operations, maintain term contracts with talent and technicians, and sustain their dominance of the film industry (Anderson 2013). In parallel, studios moved to produce and distribute smaller numbers of higher-quality big budget movies to keep drawing audiences to the movie theatres. They reduced their slates of feature films produced in-house, engaged more in co-productions, and invested in new technologies such as colour and stereophonic sound (Gil and Spiller 2007). Accordingly, they also completed their shift to assessing performance on a film-per-film basis, mostly as theatrical revenue (Hadida 2009) and Oscar nominations and awards (Ginsburgh and Weyers 1999).

The advent and rapid growth of television in the 1950s and 1960s allowed audiences to watch movies at home (Segrave 1999). The studios, however, refrained from showing their best films on television and supplied television channels essentially with lower-quality products (Anderson 2013). The expediency of linear television was also considerably constrained by programming schedules, and even after the advent of home video recording and viewing and of time-shifting, the consumption of broadcast content was limited to one device only: the television set.

The modern era began in earnest with Steven Spielberg's 1975 "Jaws" and 1977 "Close Encounters of the Third Kind", and with George Lucas's 1977 "Star Wars". After the success of these widely released and heavily promoted films, studios prioritized the search for "blockbusters"- that is, films that were likely to capture the lion share of potential audiences when released into cinemas (Gomery 2003). Blockbusters were increasingly regarded as hedge against films that were risky in terms of box-office performance, either because they dealt with unusual subjects or because they lacked familiar stars. Nowadays, most films barely breakeven. Revenues flow to a few blockbusters, and average box-office returns are dominated by extreme outcomes (Walls 2005, 2013).

$\overline{{ }^{46} \text { https://supreme.justia.com/cases/federal/us/334/131/. Accessed } 03} 012019$. 
This state of affairs is frequently criticized, with regular calls for Hollywood to turn back the clock and reject the constant search for blockbusters (Puttnam 1997), and franchise movies, which according to Academy Award winner Martin Scorsese, are lacking in "revelation, mystery or genuine emotional danger. Nothing is at risk. The pictures [...] are sequels in name but they are remakes in spirit, and everything in them is officially sanctioned because it can't really be any other way. That's the nature of modern film franchises: market-researched, audience-tested, vetted, modified, revetted and remodified until they're ready for consumption". ${ }^{47}$ Most of these calls, however, have been ignored: Paradoxically, the skewed distribution of boxoffice performance has merely served to reinforce the commitment institutional logic.

\section{References}

Aguiar, L., \& Waldfogel, J. (2018). Netflix: Global hegemon or facilitator of frictionless digital trade? Journal of Cultural Economics, 42, 419-445.

Ainslie, A., Dreze, X., \& Zufryden, F. S. (2005). Modeling movie life cycles and market share. Marketing Science, 24(3), 508-517.

Anderson, C. (2013). Hollywood TV: The studio system in the fifties (Texas film studies series). Austin: University of Texas Press.

Bakker, G. (2007). The evolution of entertainment consumption and the emergence of cinema. In M. Bianchi (Ed.), The evolution of consumption: Theories and practices (advances in Austrian economics) (Vol. 10, pp. 93-137). Emerald Group Publishing Ltd: Bingley.

Bass, R. (1994). Starring roles: How movie stardom in hollywood is won and lost. Toronto: Stoddart.

Basuroy, S., Desai, K. K., \& Talukdar, D. (2006). An empirical investigation of signaling in the motion picture industry. Journal of Marketing Research, 43, 287-295.

Baumol, W. J., \& Bowen, W. G. (1966). Performing arts: The economic dilemma. New York: The Twentieth Century Fund.

Bowser, E. (1990). The transformation of cinema: 1907-1915. Berkeley: University of California Press.

Brandenburger, A. M., \& Nalebuff, B. J. (1996). Co-opetition. New York: Doubleday.

Bughin, J., \& van Zeebroeck, N. (2017). The best response to digital disruption. MIT Sloan Management Review, 58(4), 80-86.

Carrillat, F., Legoux, R., \& Hadida, A. L. (2018). A meta-analysis of debates and assumptions about motion picture performance. Journal of the Academy of Marketing Science, 46(2), 273-299.

Chang, B. H., \& Ki, E. J. (2005). Devising a practical model for predicting theatrical movie success: Focusing on the experience good property. Journal of Media Economics, 18(4), 247-269.

Chavda, A. (2018). The downside of experimentation: Evidence from television shows. Working paper, Massachusetts Institute of Technology (November 2018).

Chesbrough, H. W. (2010). Business model innovation: Opportunities and barriers. Long Range Planning, 43(2-3), 354-363.

De Vany, A. S., \& Walls, W. D. (1999). Uncertainty in the movie industry: Does star power reduce the terror of the box office? Journal of Cultural Economics, 23(4), 285-318.

De Vany, A. S., \& Walls, W. D. (2004). Motion picture profit, the stable Paretian hypothesis, and the curse of the superstar. Journal of Economic Dynamics and Control, 28(6), 1035-1057.

Durand, R., \& Hadida, A. L. (2016). Logic combination and performance across occupational communities: The case of French film directors. Journal of Business Research, 69(7), 2371-2379.

Durand, R., Szostak, B., Jourdan, J., \& Thornton, P. H. (2013). Institutional logics as strategic resources. Research in the Sociology of Organizations, 39A, 165-201.

${ }^{47}$ Scorsese, M. (2019). The Dying Art of Filmmaking. The New York Times, 0511 2019: A, 27. 
Eisenmann, T. R., Parker, G., \& Van Alstyne, M. W. (2011). Platform envelopment. Strategic Management Journal, 32(12), 1270-1285.

Elberse, A. (2013). Blockbusters: Why big hits-And big risks-Are the future of the entertainment business. London: Faber \& Faber.

Elberse, A., \& Eliashberg, J. (2003). Demand and supply dynamics of sequentially released products in international markets: The case of motion pictures. Marketing Science, 22(3), 329-354.

Faulkner, R. R., \& Anderson, A. B. (1987). Short term projects and emergent careers: Evidence from hollywood. American Journal of Sociology, 92, 879-909.

Friedland, R., \& Alford, R. R. (1991). Bringing society back in: Symbols, practices, and institutional contradictions. In W. W. Powell \& P. J. DiMaggio (Eds.), The new institutionalism in organizational analysis (pp. 232-263). Chicago: University of Chicago Press.

Gil, R., \& Spiller, P. T. (2007). The organizational dimensions of creativity: Motion picture production. California Management Review, 50(1), 243-260.

Ginsburgh, V., \& Weyers, S. (1999). On the perceived quality of movies. Journal of Cultural Economics, 23(4), 269-283.

Glynn, M. A., \& Lounsbury, M. (2005). From the critic's corner: Logic blending, discursive change and authenticity in a cultural production system. Journal of Management Studies, 42(5), 1031-1055.

Goldman, W. (1983). Adventures in the screen trade. New York: Warner Books.

Gomery, D. (1986). The hollywood studio system. London: BFI-Macmillan.

Gomery, D. (2003). The hollywood blockbuster: Industrial analysis and practice. In J. Stringer (Ed.), Movie blockbusters. London: Taylor and Francis.

Gomez-Uribe, C. A., \& Hunt, N. (2015). The Netflix recommender system: Algorithms, business value, and innovation. ACM Transactions on Management Information Systems, 6(4), 13:1-13:19.

Greenwood, R., Diaz, A. M., Xiao Li, S., \& Lorente, J. C. (2010). The multiplicity of institutional logics and the heterogeneity of organizational responses. Organization Science, 21(2), 521-539.

Hadida, A. L. (2009). Motion picture performance: A review and research agenda. International Journal of Management Reviews, 11(3), 297-335.

Haveman, H. A., \& Gualtieri, G. (2017). Institutional Logics. In R. J. Aldag (Ed.), Oxford research encyclopaedia of business and management. Oxford: Oxford University Press.

Hennig-Thureau, T., \& Houston, M. B. (2019). Entertainment science: Data analytics and practical theory for movies, games, books, and music. New York: Springer.

Hennig-Thureau, T., Houston, M. B., \& Walsh, G. (2006). The differing roles of success drivers across sequential channels: An application to the motion picture industry. Journal of the Academy of Marketing Science, 34(4), 559-575.

Jenner, M. (2018). Netflix and the reinvention of television. New York: Palgrave Macmillan.

Jowett, G. (1985). Giving them what they want: Movie audience research before 1950. In B. A. Austin (Ed.), Current research in film: Audiences, economics and law (Vol. 1, pp. 19-35). Norwood, NJ: Ablex.

Lampel, J., \& Shamsie, J. (2000). Critical push: Strategies for creating momentum in the motion picture industry. Journal of Management, 26(2), 233-257.

Miller, D., \& Shamsie, J. (1996). the resource-based view of the firm in two environments: The hollywood film studios from 1936 to 1965. Academy of Management Journal, 39(3), 519-543.

Moul, C. C. (2005). A concise handbook of movie industry economics. Cambridge: Cambridge University Press.

MPAA. (2019). THEME report. Los Angeles: MPAA.

Musser, C. (1990). The emergence of cinema: The American screen to 1907. Berkeley: University of California Press.

Neelamegham, R., \& Chintagunta, P. (1999). A Bayesian model to forecast new product performance in domestic and international markets. Marketing Science, 18(2), 115-136.

Neelamegham, R., \& Jain, D. (1999). Consumer choice process for experience goods: An econometric model and analysis. Journal of Marketing Research, 36(3), 373-386.

Nigam, A., \& Ocasio, W. (2010). Event attention, environmental sensemaking, and changes in institutional logics: an inductive analysis of the effects of public attention to Clinton's health care reform initiative. Organization Science, 21(4), 823-841.

Ocasio, W. (1997). Towards an attention-based view of the firm. Strategic Management Journal, 18, 187-206.

Porter, M. E. (1980). Competitive strategy. New York: The Free Press.

Porter, M. E. (1985). Competitive advantage. New York: The Free Press. 
Puttnam, D. (1997). Movies and money. New York: Vintage Books.

Rao, H., Monin, P., \& Durand, R. (2005). Border crossing: Bricolage and the erosion of categorical boundaries in French gastronomy. American Sociological Review, 70, 968-991.

Ravid, S. A. (1999). Information, blockbusters, and stars: A study of the film industry. Journal of Business, 72(4), 463-492.

Regnér, P. (2005). Adaptive and creative strategy logics in strategy processes. Advances in Strategic Management, 22, 189-211.

Rusco, F. W., \& Walls, W. D. (2004). Independent film finance, pre-sale agreements, and the distribution of film earnings. In V. Ginsburgh (Ed.), Economics of art and culture. Contributions to economic analysis (Vol. 260, pp. 19-32). Amsterdam: Elsevier.

Sawhney, M. S., \& Eliashberg, J. (1996). A parsimonious model for forecasting gross box-office revenues of motion pictures. Marketing Science, 15(2), 113-131.

Segrave, K. (1999). Movies at home: How hollywood came to television. Jefferson, NC: McFarland \& Co.

Senge, P. M. (1990). The fifth discipline: The art and practice of the learning organization. New York: Doubleday.

Simonton, D. K. (2009). Cinematic success criteria and their predictors: The art and business of the film industry. Psychology and Marketing, 26(5), 400-420.

Thornton, P. H. (2001). Personal versus market logics of control: A historically contingent theory of the risk of acquisition. Organization Science, 12(3), 294-311.

Thornton, P. H. (2004). Markets from culture: Institutional logics and organizational decisions in higher education publishing. Stanford, CA: Stanford University Press.

Thornton, P. H., \& Ocasio, W. (1999). Institutional logics and the historical contingency of power in organizations: Executive succession in the higher education publishing industry, 1958-1990. American Journal of Sociology, 105(3), 801-843.

Thornton, P. H., Ocasio, W., \& Lounsbury, M. (2012). The institutional logics perspective: A new approach to culture, structure, and process. Oxford: Oxford University Press.

Tilly, C. (2006). Why? What happens when people give reasons...and why. Princeton: Princeton University Press.

Vogel, H. L. (2014). Entertainment industry economics. Cambridge: Cambridge University Press.

Walls, W. D. (2005). Modelling heavy tails and skewness in film returns. Applied Financial Economics, 15(17), 1181-1188.

Walls, W. D. (2008). Economics of motion pictures. In L. Blume \& S. Durlauf (Eds.), The new Palgrave dictionary of economics (pp. 787-791). London: Palgrave Macmillan.

Walls, W. D. (2013). Bestsellers and blockbusters: Movies, music, and books. In V. Ginsburgh \& D. Throsby (Eds.), Handbook of the economics of art and culture (pp. 185-214). Amsterdam: North-Holland.

Webster, M., \& Hysom, S. J. (1998). Creating status characteristics. American Sociological Review, 63, 361-378.

Weick, K. E. (1995). Sensemaking in organizations. Thousand Oaks, CA: Sage.

Publisher's Note Springer Nature remains neutral with regard to jurisdictional claims in published maps and institutional affiliations.

\section{Affiliations}

\section{Allègre L. Hadida ${ }^{1}$. Joseph Lampel ${ }^{2} \cdot$ W. David Walls ${ }^{3} \cdot$ Amit Joshi $^{4}$}

Joseph Lampel

joseph.lampel@manchester.ac.uk

W. David Walls

wdwalls@ucalgary.ca

Amit Joshi

amit.joshi@imd.org 
1 Cambridge Judge Business School and Magdalene College, University of Cambridge, Cambridge, UK

2 Alliance Manchester Business School, University of Manchester, Manchester, UK

3 Department of Economics, University of Calgary, Calgary, Canada

4 IMD Switzerland, Lausanne, Switzerland 